\title{
FRAMEWORK AND INDICATORS FOR A SUSTAINABLE MANUFACTURING MAPPING METHODOLOGY
}

\author{
Marja Paju \\ Juhani Heilala \\ Markku Hentula \\ Antti Heikkilä \\ VTT Technical Research Centre of Finland \\ P.O. Box 1000 \\ Espoo, 02044, FINLAND
}

Björn Johansson

Product and Production Development

Chalmers University of Technology

Gothenburg, 412 96, SWEDEN

Swee Leong

Kevin Lyons

Manufacturing Systems Integration Division

National Institute of Standards and Technology

Gaithersburg, MD 20899-8260, USA

\begin{abstract}
Increasing numbers of companies in the manufacturing industry have identified market potential for implementing sustainable and green manufacturing. Yet, current sustainability assessment tools for companies are complicated, requiring vast amounts of data and technical expertise to use them. Value Stream Mapping (VSM) is founded on lean practices, and it uses a simple method to analyze various types of material, energy, and information flow needed to bring products and services to the end-customer. The objective of this paper is to introduce and illustrate the application of a VSM-based assessment, termed as Sustainable Manufacturing Mapping (SMM). SMM takes chosen sustainability indicators into consideration and is based on VSM, Life Cycle Assessment (LCA), and Discrete Event Simulation (DES). The main phases of SMM include goal definition, identification of the sustainability indicators, and modeling the current and future state process maps. In this paper, some example indicators were identified and an SMM process map was generated for illustrative purposes.
\end{abstract}

\section{INTRODUCTION}

The design of a manufacturing system involves a number of interrelated subjects, such as tooling strategy, material-handling methods, system size, process and material flow configuration, flexibility needed for future engineering changes, production methods, capacity adjustment, and production floor layout strategy. Sustainable manufacturing system design takes into account economic and ecological constraints as well. Thus, there are additional parameters to be handled simultaneously, and this increases the challenge in the design process. Several modeling and simulation techniques that exist for support of the design, development, and analysis process, also can be employed for sustainability assessment.

In recent years, the definition of sustainable manufacturing has raised discussion. The U.S. Department of Commerce helped set the stage for a new initiative by defining Sustainable Manufacturing "as the creation of manufactured products that use processes that minimize negative environmental impacts, con- 
Paju, Heilala, Hentula, Heikkila, Johansson, Leong, and Lyons

serve energy and natural resources, are safe for employees, communities, and consumers and are economically sound" (The U.S. Department of Commerce 2010). This considers many similar aspects as the definitions given by the Organization for Economic Cooperation and Development (2009) and the Lowell Centre for Sustainable Production (2010).

This paper introduces a new methodology termed as Sustainable Manufacturing Mapping (SMM), which will be discussed more detailed in Section 3. This study is closely related to the work done by Heilala, Paju, and Tonteri (2009), who discussed and compared three methods: Value Stream Mapping (VSM), Discrete Event Simulation (DES), and Life Cycle Assessment (LCA). LCA method is standardized as International Standardization Organization (ISO) 14040 (2006) and ISO 14044 (2006). As for VSM, it is counted as a lean technique for improving efficiency by identifying wasteful material, energy and information flows. DES is used to model sequence of operations, e.g., in manufacturing, and it enables dynamic analysis. LCA includes an environmental assessment considering products' energy consumption, use of raw materials waste generated, and so forth. These methods have different applications but can complement one another as given in Table 1.

Table 1. Characteristics of VSM, LCA, and DES used in SMM, preferred features highlighted in italics

\begin{tabular}{|c|c|c|c|}
\hline Feature & VSM & LCA & DES \\
\hline Dynamic assessment & $\begin{array}{l}\text { Deterministic, stan- } \\
\text { dard or average pa- } \\
\text { rameter }\end{array}$ & $\begin{array}{l}\text { Deterministic, stan- } \\
\text { dard or average pa- } \\
\text { rameter }\end{array}$ & $\begin{array}{l}\text { Dynamic event relationships, } \\
\text { probabilistic parameters }\end{array}$ \\
\hline Publicly available data & & $\begin{array}{c}\text { Public LCA data } \\
\text { available }\end{array}$ & \\
\hline Visualization & $2 \mathrm{D}$ process map & $\begin{array}{l}\text { Limited process } \\
\text { view }\end{array}$ & $\begin{array}{c}3 D \text { visualization and anima- } \\
\text { tion }\end{array}$ \\
\hline Simplified & User-friendly tool & Experts tool & Experts tool \\
\hline Standardized & $\begin{array}{llr}\text { Industrial de } & \text { facto } \\
\text { standard for } & \text { lean } \\
\text { manufacturing } & \\
\end{array}$ & $\begin{array}{l}\text { Standardized ISO } \\
14040, \text { ISO } 14044\end{array}$ & Partially \\
\hline $\begin{array}{l}\text { Framework for environmen- } \\
\text { tal impact analysis }\end{array}$ & $\begin{array}{l}\text { Methodology has } \\
\text { been presented }\end{array}$ & The main tool & $\begin{array}{l}\text { Mostly research initiatives, } \\
\text { also commercial solution en- } \\
\text { tering the market }\end{array}$ \\
\hline
\end{tabular}

SMM combines elements from environmental assessment tools, simulation, and value stream mapping for a model that is simple to use, has high visualization, and provides a framework for environmental assessment as well as assessment of other sustainability indicators. The environmental indicators are the main focus of this paper.

\section{MODELS FOR SUSTAINABLE MANUFACTURING}

This section discusses the chosen existing methods and their main features. The discussion provides the background for the proposed methodology to be described in Section 3.

\subsection{Overview of Models}

Simulation and other assimilated models can be classified in multiple ways. Law and Kelton (1991) categorized them as static, when time plays no role (particular time or steady state), like the Monte Carlo simulation; dynamic, when the model represents a system that evolves over time; deterministic, not probabilistic, i.e., random components; stochastic, at least one random input component; continuous; or discrete. Harrell and Tumay (1995) classified them as symbolic models, analytic models, and simulation models.

Symbolic models, such as process flow diagrams, flowcharting, and Integrated DEFinition (IDEF), are suitable for communication, easy to understand, and quick to develop. The focus on the processes in the system and are not aimed to resolve resource issues and operational problems too early. The disadvan- 
Paju, Heilala, Hentula, Heikkila, Johansson, Leong, and Lyons

tages include lack of details, little or no quantitative measure of system elements or description of elements, activities, and relationships, and failure to capture the system dynamics. Symbolic models are static models.

Analytic models, such as mathematical formulas, queue formulas, and linear programming, can give a quick answer. Some are able to give an optimum solution without going through trial and error. Their disadvantages include simplified assumptions that are often unable to account for random behaviors, and, thus a simplified solution to complicated problems.

Factory simulation measures the effects of process variability and interdependencies on overall system performance. A simulation creates an artificial history of the system. The disadvantages are that models can be difficult to construct - model building can be time-consuming and challenging, and it is more descriptive than prescriptive.

In principle, a combination of the above-mentioned methods should aid engineers to speed up the design process and improve decision-making. Inline the proposed SMM combines VSM, DES, and LCA to facilitate such improvements.

\subsection{DES and VSM}

VSM is a simple-to-use symbolic process modeling tool. It specifies the activities, cycle times, downtimes, and delays, and identifies bottlenecks and non-value-added activities in the production or in the logistics. A snapshot of the process activities in production may be created based on average data. Conventional VSM is created for one product or product family with a pen and paper, although there are numerous VSM software tools. Modeling of more complex systems, e.g., multiple production lines, is possible but requires a platform that supports hierarchical models. (Heilala, Paju, and Tonteri 2009.)

By adding simulation to VSM, it is possible to add parameters to evaluate bottlenecks, buffer levels, and changing production volumes. Simulation allows adding parameters and modeling scenarios and uncertainties, which the traditional map cannot offer. Solding and Gullander (2009) pointed out simulation is needed to make the VSM more dynamic and introduced a simulation-based VSM that made use of Automod and Excel.

There are ways to automate the creation of a simulation model from the digital VSM model. Selected software tools such as Process Simulator, Simul8, and VisioSim support simulation of the process maps created with Microsoft Visio, while others such as Arena, SimCad, and Extend offer specific VSM templates. More recently, the Connecticut Centre for Advanced Technology, Inc. (CCAT) demonstrated the ability of semi-automatically converting VSM models created with Visio to QUEST simulation models. The CCAT development is based on the use of the Core Manufacturing Simulation Data (CMSD). CMSD standard is developed under the Simulation Interoperability Standards Organization (SISO) (Lee et al. 2008). (OR/MS Today 2009.)

\subsection{LCA, DES, and VSM}

Most of the environmental assessment methods consider a facility or supply chain as a system of which material and energy flows move in and out of the system. Energy and material cannot disappear but can change their form. Methods and software tools can be divided for example into two groups: methods that aim at calculating a quantitative balance, mainly inside a facility (e.g., material flow analysis), and those that incorporate Life Cycle Thinking (LCT) and include also a qualitative analysis through an environmental impact assessment (e.g., LCA, carbon footprint). Life Cycle Thinking is a management philosophy that seeks to identify possible improvements to goods and services in the form of lower environmental impacts across all life cycle stages. Life cycle refers to raw material extraction and conversion, manufacture and distribution, use and re-use, recycling of materials, energy recovery, and ultimate disposal (European Commission LCT 2010).

LCA is based on LCT and consists of four stages: goal and scope definition, data inventory analysis, environmental impact assessment, and interpretation of the output data for application use. The result can be given in the most compact form as one index, which can be done with specific impact assessment me- 
Paju, Heilala, Hentula, Heikkila, Johansson, Leong, and Lyons

thods such as Eco-indicator 99 (Eco-indicator 99 2010). At the end the interpretation complements the assessment according to the chosen use application. This can be, for example, an internal product design or creating a environmental product declaration for stakeholder communication. (Heilala, Paju, and Tonteri 2009.)

Environmental analysis was combined with a simulation model in the SIMTER tool (Heilala et al. 2008). SIMTER is a holistic, integrated production system simulation and environmental analysis method. It serves as a cross-disciplinary decision-making tool for sustainable and simultaneous analysis of the level of automation, human ergonomics, productivity, and environmental aspects of the production system. The SIMTER tool enables environmental assessment with Microsoft (MS) Excel, a 3D robotics and factory simulation tool, and 3D Create from Visual Components. The prototype tool is aimed at use by manufacturing system design engineers in small and medium-sized enterprises. In SIMTER, the selected environmental information was taken from the European Commission's public Life Cycle Inventory (LCI) database. The SIMTER development could be enhanced with other commercial simulation software.

Additional examples combining simulation and environmental analysis can be found in Johansson et al. (2008), Joschko et al. (2009), and Moeller et al. (2009). A number of commercial tools are also available. The latest version of Simul8 DES software provides carbon monitoring, while Witness Power with Ease optimizes energy use. System Dynamics (SD) modeling can also be used for environmental aspects analysis (Kibira, Jain, and McLean 2009).

VSM and environmental analysis have also been merged together in some application. The US Environmental Protection Agency has introduced the Lean and Environment toolkit (EPA 2007), which is meant for lean practitioners to improve their environmental performance (EPA 2007). Simons and Mason (2002) proposed Sustainable Value Stream Mapping (SVSM) in optimizing logistics chain and Fearne and Norton (2009) discussed SVSM in the food industry. Lean focuses on eliminating wasteful operations by identifying value added and non-value added activities and therefore can be used to facilitate environmental improvements.

In the proposed methodology, DES works as an add-on element and VSM is considered as a visualization technique used to implement environmental indicators.

\subsection{Environmental Indicators}

Indicators are used for compressing, manipulating and understanding large amounts of information (Krajnc and Glavic 2003). According to Greiner (2001), an indicator has three main purposes in companies: to raise awareness and understanding of the issues it indicates, to help in decision-making, and to measure the achievement of established goals. A good indicator is described as understandable, reliable, and accessible by Sustainable Measures (2010).

The use of indicators varies in different organizations. One example is to divide the indicators into five sequential stages, which are built on one another as shown in Figure 1 (Greiner 2001). At the first level, the facility conformance indicators are based on legislation or other external requirements. For instance, an emission limit is given in the facility's environmental permission. At the second level the indicators relate to the materials and energy usage, byproducts, emissions and waste. On the third level, the indicators are used to aggregate emissions, wastes etc. from different sources and express them as potentials. For instance Global Warming Potential (GWP) is measured in $\mathrm{kg}$ of carbon dioxide equivalent (CO2e), which considers carbon dioxide, methane and other emissions that have an impact on global warming. At the fourth level, the scope is broadened from the facility to the supply chain and ultimately to the whole life cycle including indicators from recycling and logistics (e.g., $\mathrm{CO} 2$ emissions from the transportation process). At the last level, the indicators are not determined by the company, but by the surrounding society. These indicators describe the kind of production that is in balance with quality of life and the ecological carrying capacity. (Greiner 2001.) 
Paju, Heilala, Hentula, Heikkila, Johansson, Leong, and Lyons

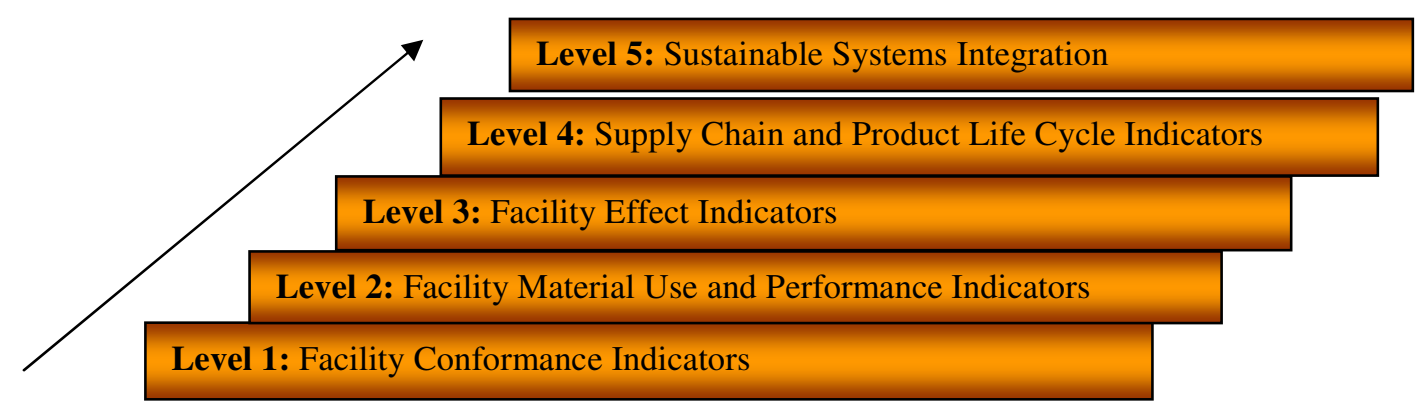

Figure 1: A model of five different stages of environmental indicators (Greiner 2001)

When starting to use indicators, it is recommendable for companies to begin with a couple of key indicators (Krajnc and Glavic 2003). The indicators should be determined so that the system boundaries and time line are clear; e.g., whether the data are for yearly or daily production. For example, LCA uses the data gathered from the whole life cycle of the product (ISO 14040 2006), and the input data are most commonly expressed per year of production and converted for the assessment per product.

Additionally, the data aggregation level should be decided. Each parameter, measured or calculated, may be expressed separately as e.g., in mass, energy, temperature, or radiation dosage units. The parameters can also be classified, for example, into liquid, solid, and gaseous emissions. To take the quantitative data to the decision-making level, analysis of the environmental impacts is crucial. In LCA, the parameters are divided into impact categories such as Global Warming Potential (GWP) that takes into account many gaseous compounds. Impact assessment may also include weighting of impact categories against each other. Also, the interdependencies between the parameters should be noted. For example, the energy consumption is related to the $\mathrm{CO} 2$ emissions.

There is yet no consensus of a standard set of sustainability indicators, though there are several sustainable indicator sets defined by various organizations as described in Feng and Joung (2009). Some standards have already been set. For example, ISO 14031 (1999) provides guidelines for environmental performance evaluation in the identification and selection of environmental indicators. The kinds of indicators used in different manufacturing companies can be defined in the environmental management system. When the set of indicators is determined separately for each facility, comparing the facilities with different types of indicators may be problematic.

\section{SUSTAINABLE MANUFACTURING MAPPING}

This section describes a framework of the new methodology SMM. At the end of this section, an example SMM process map is presented.

\subsection{Proposed Methodology Framework}

SMM, shown in green in Figure 2, is an integrated visualization and monitoring method for environmental impacts and production control. The result from SMM is a map, which is suitable for communication between the production floor and the management level. The core driver of the method is the improvement targets that define the environmental, production economic, and social indicators used in the SMM. The improvements are illustrated in the current and future state map view with the chosen indicators. Improvement targets may be changed according to the company's stakeholders. For instance, the change can be initiated by customers' growing concern about the products' environmental impact. The map supports the goals, which can be defined, e.g., in organization's environmental policy, and setting targets for continuous improvement through the Plan-Do-Check-Act cycle. The main output of SMM are material and energy balances in figures and graphs to achieve the strategic goals (future state map). 
Paju, Heilala, Hentula, Heikkila, Johansson, Leong, and Lyons

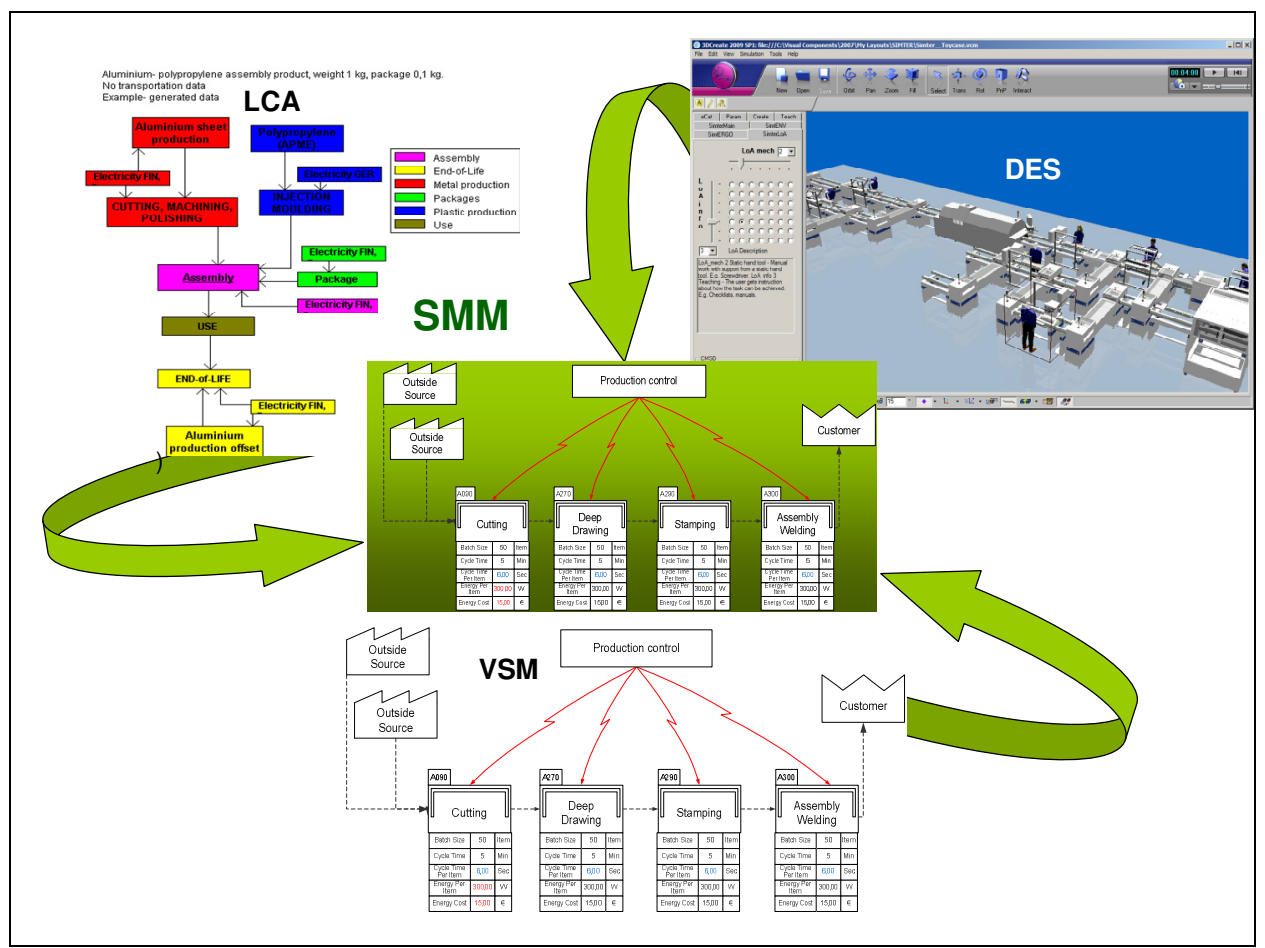

Figure 2: Schematic framework for SMM using LCA, DES, and VSM

As shown in Table 1 and Figure 2, SMM is based on LCA, DES and VSM methods. From the LCA method SMM borrows the goal and scope definition, and the environmental data, e.g., from the Life Cycle Inventory (LCI) database (European Commission LCI 2010). SMM uses VSM as its platform, taking into account the principle of symbolic process mapping. The assessment can be conducted with a VSM-based process-mapping tool. LCA and VSM are based on average data and that is why DES is required to make the assessment dynamic.

The initial step of SMM is to set the goal and scope. The goals should be as accurate as possible, including the timeline, and be expressed in currency units, e.g., "reduce the operational costs by $10 \%$ in one year", if cost reduction is the ultimate goal. A cost reduction may be achieved, e.g., by increasing the material efficiency and reducing the amount of waste. The goal can also be based on aggregated indicators, such as global warming potential expressed in $\mathrm{kg}$ of $\mathrm{CO} 2 \mathrm{e}:$ "Reduce the global warming potential by $50 \%$ in 3 years." Examples for system boundaries are the cradle-to-grave and gate-to-gate approach, meaning that the assessment looks only at parts of the total life cycle (cradle-to-cradle).

Using the life cycle approach instead of a facility scope the shifting the environmental burden (e.g., due to outsourcing operations contributing to the goal moving to a different country) will be avoided. Thus, a goal including a statement about the system boundaries is, for instance, to "calculate the carbon weight of the sales transportation and the facility operations." When using the facility scope, the major indirect operations outside the facility, such as electricity production, should be included into the facility's environmental balance.

The next step includes choosing the right indicators. It precedes data acquisition. The choice of reference unit is also included. All the data presented on the map must be adjusted to the reference unit, which can be one product or yearly production. A data editor view should be created so that the balance can be seen for one or multiple products (e.g., yearly production, batch size). Each process should have a limited number of visual indicators on the actual map, and not all processes have the same indicators. 
Paju, Heilala, Hentula, Heikkila, Johansson, Leong, and Lyons

\subsection{Sustainability Indicators}

SMM connects the production parameters to sustainability indicators. VSM and DES are commonly used for manufacturing system analysis and development. Normally the methods only show some selected production efficiency key performance indicators. At the same time, both methods create information about the production parameters needed for the calculation and analysis of environmental aspects. For example, VSM and DES can provide bookkeeping of production volume, number of products manufactured, cycle time, utilization, and equipment running time.

Table 2 represents a compilation of indicators that may be used as examples. SMM is based on casespecific definition of sustainability indicators according to the assessment goals however.

Table 2: An example categorization of sustainability manufacturing parameters

\begin{tabular}{|l|c|c|c|}
\hline Category name & Sub-categories & Metrics, examples & Units \\
\hline Energy & Energy type & Electricity, heat, cooling & $\mathrm{kWh}, \mathrm{MJ}$ \\
\hline \multirow{3}{*}{ Materials } & Raw materials & Steel bars, packaging materials & $\mathrm{kg}$ \\
\cline { 2 - 4 } & Auxiliary materials & Lubrication oil, compressed air, process water & $\mathrm{m}^{3}, \mathrm{~kg}$ \\
\cline { 2 - 4 } & Waste materials & Steel and plastic to recycle, waste oil & $\mathrm{kg}$ \\
\hline \multirow{3}{*}{ Emissions } & Air emission & Nitrogen oxides, heavy metals & $\mathrm{kg}$ \\
\cline { 2 - 4 } & Water emissions & Chemical oxygen demand & $\mathrm{kg}$ \\
\hline \multirow{2}{*}{ Production } & Time & Throughput time, cycle time & $\mathrm{d}, \mathrm{s}$ \\
\cline { 2 - 4 } & Production quantity & Piece & Several \\
\hline \multirow{2}{*}{ Logistics } & Mode of conveyance & Vehicle type, load rate, capacity & $€, \$$ \\
\hline \multirow{2}{*}{ Costs } & Unit cost & Raw material, energy costs & $€, \$$ \\
\cline { 2 - 4 } Social & Investment cost & Machine, robot, facility & $\mathrm{d} / \mathrm{a}$ \\
\cline { 2 - 4 } & Staff & Number of man-hours of work, work absence days \\
\hline
\end{tabular}

Standardized indicators are needed to communicate in-between, and to compare different companies or facilities. One of the main challenges is that different types of indicators use different reference unit. For example commonly used production indicators follow the work cycle or yearly production volume while staff-related social indicators such as working hours and work absence days are commonly bound with time. This is why the identification of the reference unit is an essential part of SMM.

Choosing of indicators is dependent on the goal for SMM. Goal could be, for instance, to reduce the carbon emissions derived from the production operations and to illustrate the monetary benefit gained from the respective reduction. The assessment is started by identifying, in a systematic way, the material and energy flows as well as the operations that contribute to the wanted environmental impact category and make the energy and material balances. The most suitable indicators to map could be heat energy $(\mathrm{MJ})$, electricity consumption $(\mathrm{kWh})$ for each unit process in the facility, and energy unit costs (e.g., \$ per $\mathrm{kWh}$ ). The electricity consumption and other possible emissions are then translated into Global Warming Potentials measured in $\mathrm{kg}$ of CO2e. Carbon dioxide-related emissions are also emitted outside the facility, e.g., from transportation. The emissions depend on the vehicle type and the fuel used as well as the payload rate. The transportation distances to the treatment facility and the weight of the cargo both contribute to the calculations.

Process or material specific input data for SMM will be either obtained from readily produced sources or the data need to be produced, e.g., through additional measurements. For an assembly product, such as a steel cup, the essential existing input data are the Bill of Materials (BOM). In brief, the list specifies each part as the simplified example BOM given below:

- Lid: 40 g plastic

- Bottom cover: $30 \mathrm{~g}$ plastic

- Handle: 20 g plastic

- Body: $160 \mathrm{~g}$ stainless steel 
Paju, Heilala, Hentula, Heikkila, Johansson, Leong, and Lyons

With the BOM, environmental data from cradle to the factory gate can be taken from the public LCI data sets, e.g. European Reference Life Cycle Database (ELCD) (European Commission LCI 2010). This requires the public database to include the corresponding material or operation. The current ELCD data sets are available for energy production, materials and manufacturing processes, end-of-life treatment, energy carriers and technologies, material production, and transport services. Each data set has dozens of parameters (emissions, waste, materials, and energy flows), which implies that not all the data can be presented on the SMM map. Therefore, an LCA software tool may be needed to modify the data into subcategories.

\subsection{Computer Modeling}

To build an SMM computer model, the first step is to identify the essential manufacturing and auxiliary processes. After that, the actual manufacturing processes will be converted to a process map with a software tool. For this purpose, eVSM software (eVSM 2010) was used. It is based on "drag and drop" VSM modeling. A snapshot of the system for steel cup manufacturing is illustrated in Figure 3, in which a representative process flowchart for steel cup manufacturing is shown.

Figure 3 presents a simplified model of the SMM, including as an example of two key performance indicators (electricity and waste amount). Corresponding graphs are created. Besides the facility unit processes, indicators from external processes, such as electricity production, may be considered. SMM is carried out with eVSM or another process mapping software. An additional analysis can be accomplished with some simulation tools. Simulation allows "what-if" scenarios and modeling queues in the production systems. The results from running a simulation model can be taken to SMM, such as lead times, energy consumption, and waste materials. All results from simulation can include variances due to specific events and time. Hence time is a new dimension, which contributes added value through simulation.

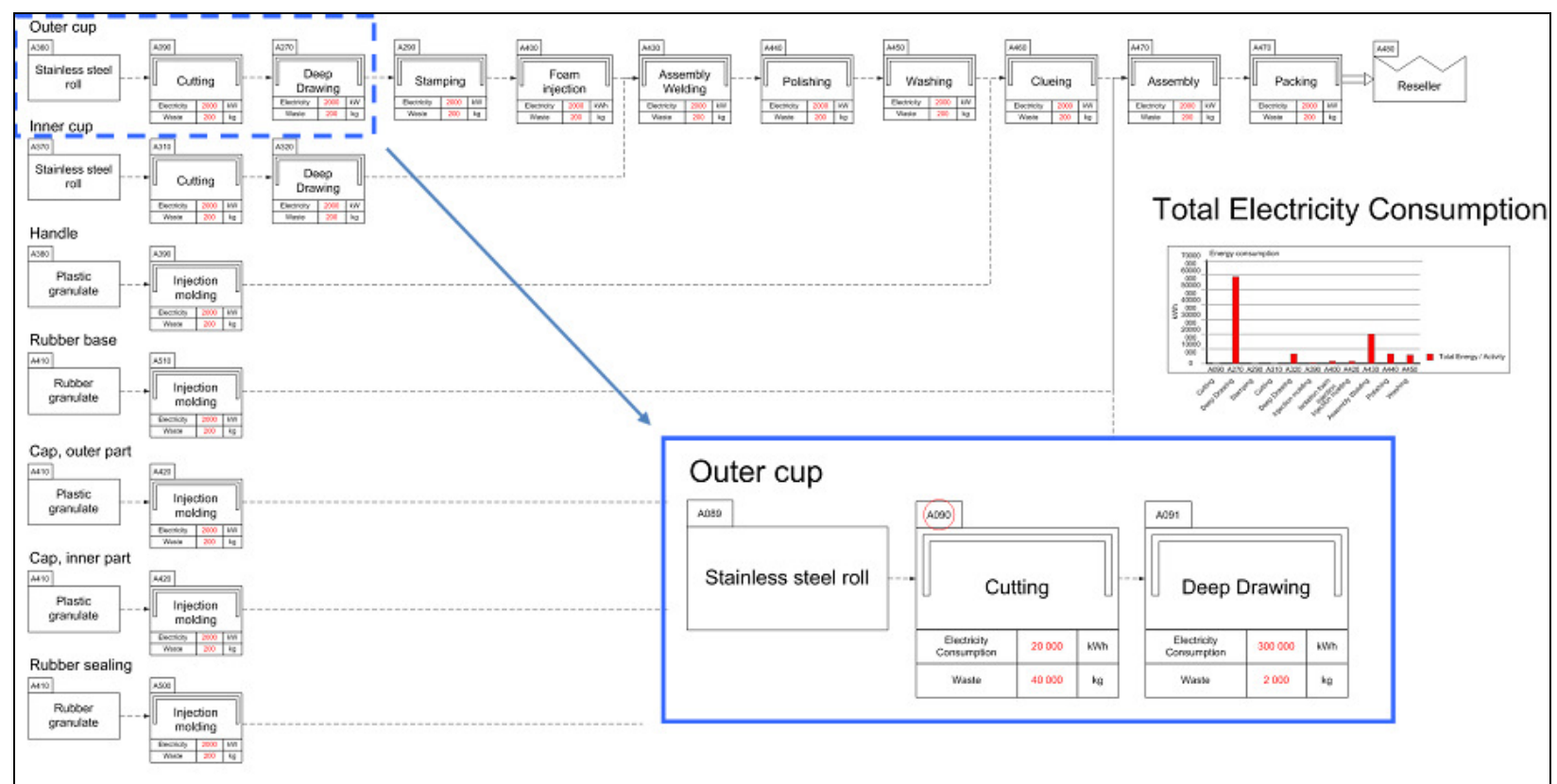

Figure 3: Steel cup's production map with fictitious values, while electricity consumption and waste amount are the chosen indicators.

\section{DISCUSSION}

Controlling the environmental impacts is becoming more important in the manufacturing industry, as the goal is shifting from the conventional end-of-pipe technology to closed material loops, zero waste, and 
Paju, Heilala, Hentula, Heikkila, Johansson, Leong, and Lyons

zero carbon (Ball et al. 2009) facilities. This shift can be accelerated with tools and methods that look at both the future and current states emphasizing continuous improvement.

Methods and tools for environmental assessment in the discrete part manufacturing industry can be divided into two categories: those that are used primarily for the assessment of environmental aspects, such as LCA, and those that use environmental assessment as an add-on element. Add-on tools require less effort to adapt to existing manufacturing modeling tools, but they compromise on comprehensiveness in the environmental assessment part. There exist few tools that include operations beyond the facility. The environmental assessment-oriented tools are more comprehensive but require multidisciplinaryexpertise to use. Data collection could be a bottleneck to assessment methods that take a life cycle approach.

This paper proposes a framework for a process mapping method, Sustainable Manufacturing Mapping (SMM). The new method uses the principles from existing methods, VSM, DES, and LCA. SMM takes a goal-oriented approach, a principle that is known in LCA (ISO 14040 2006). Choosing the right indicators according to the goal, and setting the system boundaries are essential steps for SMM. The challenge of the goal-oriented approach is that, comparing with different systems may be problematic, as the assessment does not use the same indicators.

In theory, SMM can use publicly available LCI data as input. While the amount of publicly available commercial LCI data is increasing, consistency is needed. For example, nomenclature and naming convention for materials and energy flows in the LCI databases are not consistent and still pose a challenge. For the same component there exists several material and energy flows yet they have different names. This increases the amount of manual work required.

Future research could address additional details of the simulation model while considering monetary and social indicators for incorporation into the SMM. The development of SMM could greatly benefit from industrial case studies.

\section{ACKNOWLEDGMENTS}

This publication is part of the Eco-Efficient Production "EKOTEHO", a research project at VTT, the Technical Research Centre of Finland. The authors wish to acknowledge the financial support received from the Finnish Funding Agency for Technology and Innovation (TEKES) and Finnish industry. The funding for this research is partly granted by the Swedish Foundation for Strategic Research (SSF), through ProViking as well as the Swedish Agency for Innovation Systems (VINNOVA) through FFI (Strategic Vehicle Research and Innovation). Work for the paper was supported through a researcher exchange with NIST (National Institute of Standards and Technology) sponsored by SLIM (Sustainable and Lifecycle Information-based Manufacturing) program.

\section{DISCLAIMER}

No approval or endorsement of any commercial product by the National Institute of Standards and Technology is intended or implied. Certain commercial equipments, software, instruments, or materials are identified in this report to facilitate better understanding. Such identification does not imply recommendations or endorsement by the National Institute of Standards and Technology, nor does it imply the materials, software, or equipment identified are necessarily the best available for the purpose.

\section{REFERENCES}

Ball, P.D., S. Evans, A. Levers, and D. Ellison. 2009. Zero carbon manufacturing facility - towards integrating material, energy, and waste process flows. Proceedings of the Institution of Mechanical Engineers, Part B: Journal of Engineering Manufacture, 223 (9). ss. 1085-1096.

Eco-indicator 99. What is the Eco-indicator? Available via <http://www.pre.nl/eco-indicator99/ecoindicator_application.htm> [Accessed June 14, 2010]. 
Paju, Heilala, Hentula, Heikkila, Johansson, Leong, and Lyons

EPA. 2007. The Lean and Environment Toolkit. U.S. Environmental Protection Agency. Available via <http://www.epa.gov/lean/toolkit/LeanEnviroToolkit.pdf>. [Accessed March 30, 2010].

European Commission LCI. 2010. ELCD 2.0. Life Cycle Inventory (LCI) data sets. Available via $<$ http://lca.jrc.ec.europa.eu/lcainfohub/datasetCategories.vm> [Accessed June 08, 2010].

European Commission LCT. 2010. Joint Research Center. Institute for Environment and Sustainability. Life Cycle Thinking. Available via <http://lct.jrc.ec.europa.eu/> [Accessed July 15, 2010].

eVSM. 2010. Software homepage. Available via < http://www.evsm.com/>. [Accessed June 14, 2010].

Feng, S.C., and C.B. Joung. 2009. An Overview of a Proposed Measurement Infrastructure for Sustainable Manufacturing. Proceedings of the 7th Global Conference on Sustainable Manufacturing. Available via <http://www.nist.gov/customcf/get_pdf.cfm?pub_id=904166>. [Accessed June 29, 2010].

Fearne, A., and A. Norton. 2009. Sustainable Value Stream Mapping in the Food Industry. In: Waldron, K., ed. Handbook of Waste Management and Co-Product Recovery in Food Processing. Woodhead Publishing, Cambridge. ISBN 9781845693916.

Greiner, T.J. 2001. Indicators of Sustainable Production - Tracking Progress. A Case Study on Measuring Eco-Sustainability at Guilford of Maine, Inc.1. Greiner Environmental, Lowell Center for Sustainable Production. Available via $<$ http://sustainableproduction.org/downloads/Guilford\%20Case\%20Study.pdf> [Accessed June 08, 2010].

Harrell, C., and K. Tumay. 1995. Simulation made easy. A manager's guide. Industrial Engineering and Management Press. Institute of Industrial Engineers. ISBN 0-89806-136-9.

Heilala, J., M. Paju, and H. Tonteri. 2009. Environmental Aspects Analysis of Products and Production Systems. Proceedings of the Sixth International Symposium on Environmentally Conscious Design and Inverse Manufacturing - EcoDesign2009. Sapporo, Japan, 7-9 December, 2009 (CD-ROM). Japan Society of Mechanical Engineering.

Heilala, J., S. Vatanen, J. Montonen, H. Tonteri, B. Johansson, J. Stahre, and S. Lind. 2008. SimulationBased Sustainable Manufacturing System Design. In Proceedings of the 2008 Winter Simulation Conference, eds. S. J. Mason, R. R. Hill, L. Mönch, O. Rose, T. Jefferson, J. W. Fowler, 1922-1930. Piscataway, New Jersey: Institute of Electrical and Electronics Engineers, Inc.

ISO 14031. 1999. Environmental Management. Environmental Performance Evaluation. Guidelines

ISO 14040. 2006. Environmental Management. Life Cycle Assessment. Principles and Framework.

ISO 14044. 2006. Environmental Management. Life Cycle Assessment. Requirements and Guidelines.

Johansson, B., J. Stahre, J. Berlin, K. Östergren, B. Sundström, A-M. Tillman. 2008. Discrete Event Simulation with Lifecycle Assessment Data at A Juice Manufacturing System. In proceedings of FOODSIM 2008 Conference, University College Dublin, Ireland.

Joschko, P., B. Page, V. Wohlgemuth. 2009. Combination Of Job Oriented Simulation With Ecological Material Flow Analysis As Integrated Analysis Tool For Business Production Processes. In Proceedings of the 2009 Winter Simulation Conference, eds. M. D. Rossetti, R. R. Hill, B. Johansson, A. Dunkin and R. G. Ingalls, 1457-1465. Piscataway, New Jersey: Institute of Electrical and Electronics Engineers, Inc.

Kibira, D., S. Jain, C. McLean. 2009. A System Dynamics Modeling Framework for Sustainable Manufacturing. Proceedings of the 27th Annual System Dynamics Society Conference. Available via <http://www.nist.gov/customcf/get_pdf.cfm?pub_id=903291> [Accessed June 30, 2010].

Krajnc, D., P. Glavic. 2003. Indicators of Sustainable Production. Clean Techn. Environ. Policy, 5 (2003). ss. 279-288.

Law, A.M., W.D. Kelton. 1991. Simulation Modeling \& Analysis. 2. edition. ISBN 0-07-036698-5.

Lee, Y.T., F.H. Riddick, C.R. McLean, S.K. Leong. 2008. Current Activities Related to the Core Manufacturing Simulation Data Standards Development Effort. Proceedings of the Fall 2008 Simulation Interoperability Workshop, USA. Available via $<$ http://www.nist.gov/customcf/get_pdf.cfm?pub_id=824688> [Accessed July 23, 2010].

Lowell Centre for Sustainable Production. 2010. University of Massachusetts Lowell. Available via $<$ http://www.sustainableproduction.org/abou.what.php> [Accessed June 08, 2010]. 
Paju, Heilala, Hentula, Heikkila, Johansson, Leong, and Lyons

Moeller, A., M. Prox, M. Schmidt, H. Lambrecht. 2009. Simulation and Optimization of Material and Energy Flow Systems. In Proceedings of the 2009 Winter Simulation Conference, eds. M. D. Rossetti, R. R. Hill, B. Johansson, A. Dunkin and R. G. Ingalls, 1444 - 1455. Piscataway, New Jersey: Institute of Electrical and Electronics Engineers, Inc.

Organization for Economic Cooperation and Development. 2009. Overview of the OECD Sustainable Manufacturing Toolkit Prototype. Available via <http://www.oecd.org/dataoecd/34/25/44280332.pdf> [Accessed June 14, 2010].

OR/MS Today. 2009. Simulation Software Survey. Available via $<$ http://www.lionhrtpub.com/orms/surveys/Simulation/Simulation.html> [Accessed June 30, 2010].

Simons, D., R. Mason. 2002. Environmental and Transport Supply Chain Evaluation with Sustainable Value Stream Mapping. Proceedings of the $7^{\text {th }}$ Logistics Research Network Conference, UK.

Solding, P., P. Gullander. 2009. Concepts for Simulation Based Value Stream Mapping. In Proceedings of the 2009 Winter Simulation Conference, eds. M. D. Rossetti, R. R. Hill, B. Johansson, A. Dunkin and R. G. Ingalls, 2231-2237. Piscataway, New Jersey: Institute of Electrical and Electronics Engineers, Inc.

Sustainable Measures. 2010. Characteristics of effective indicators. Available via <http://www.sustainablemeasures.com/Indicators/Characteristics.html> [Accessed June 08, 2010].

The US Department of Commerce. 2010. The International Trade Administration and The U.S. Department of Commerce's definition for Sustainable Manufacturing. Available via $<$ http://www.trade.gov/competitiveness/sustainablemanufacturing/how_doc_defines_SM.asp> Accessed June 08, 2010].

\section{AUTHOR BIOGRAPHIES}

MARJA PAJU is a research scientist at VTT, the Technical Research Centre of Finland, and currently works as a project manager on the research project Eco-Efficient Production. Paju has a Master's Degree in Environmental Technology and is a guest researcher at the National Institute of Standards and Technology in Gaithersburg, MD, USA. Paju's current research interests are different methods, tools and data for environmental and sustainable assessment in the manufacturing industry. Paju's email address is $<$ marja.pajulvtt.fi>.

JUHANI HEILALA is a senior research scientist at VTT, the Technical Research Centre of Finland. Heilala has 20 years' experience in robotics and production system development. Simulation has been the key technology in his previous projects. Heilala's current research interests include expanding simulation and modeling from system design and analysis methods to simulation-based manufacturing operation planning, and integration of production system simulation with other analysis methods. Heilala's current research project studies include manufacturing energy efficiency and sustainability issues. Heilala's email address is <juhani.heilala@vtt.fi>

MARKKU HENTULA is a senior research scientist at VTT, the Technical Research Centre of Finland. Hentula has 20 years of broad experience in production system development, simulation technology, production control systems, production automation, and various enabling technologies (e.g., robotics, RFID, machine vision systems). In addition to the above, Hentula's current research interests include sustainable manufacturing. Hentula's email address is <markku.hentula@vtt.fi>.

ANTTI HEIKKILÄ is a research scientist at VTT, the Technical Research Centre of Finland. Heikkilä has more than 30 years' expertise in the development of models and software tools for the simulation and optimization of the wood conversion value chain - from forest to final wood products. The development work has been carried out with strong industrial co-operation. Heikkilä's current research interests lie in software development for the wood product industry, especially sawmills. Sustainability is a common research agenda. Heikkilä's email address is <antti.heikkila@vtt.fi>. 
Paju, Heilala, Hentula, Heikkila, Johansson, Leong, and Lyons

BJÖRN JOHANSSON is Assistant Professor of Product and Production Development at Chalmers University of Technology and serves as Production Modeling Corporation Director for the Swedish office in Gothenburg. Johansson is also a guest researcher at the National Institute of Standards and Technology in Gaithersburg, Maryland, USA. Johansson was a WSC proceedings co-editor in 2009. Johansson's research interests lie in the area of discrete event simulation applied to manufacturing industries, including environmental effects modeling, modular modeling methodologies, software development, user interfaces, and input data architectures. Johansson's email address is <wsc10 johansson@ gmail.com>.

KEVIN LYONS is a Senior Research Engineer at the Manufacturing Engineering Laboratory (MEL), the National Institute of Standards and Technology (NIST). Lyons currently supports the Sustainable Manufacturing Program at NIST. Lyons's research interests are design, manufacturing unit processes, simulation and modeling, and nanomanufacturing. From 2004 through 2006, Lyons served as Program Director for the Nanomanufacturing Program at the National Science Foundation (NSF). From 2000 to 2004, he served as Program Manager for the Nanomanufacturing Program at NIST. From 1996 to 2000, he served as Program Manager with the Defense Advanced Research Projects Agency (DARPA) where he managed advanced design and manufacturing projects. From 1977 to 1992, Lyons worked in industry, in various staff and supervisory positions in engineering marketing, product design and analysis, factory automation, and quality engineering. Lyon's email address is <kevin. lyons@nist.gov>.

SWEE LEONG has been a senior manufacturing engineer at the Manufacturing Simulation and Modeling Group at the National Institute of Standards and Technology (NIST) Manufacturing System Integration Division since 1994. Prior to joining NIST, he worked at Ford Motor Company, John Deere, and IBM on different factory automation projects. Leong's research interests lie in modeling and simulation activities for the manufacturing industries, and engineering tools integration. Leong currently manages the Simulation Standards Consortium at NIST and is Chairman of the Core Manufacturing Simulation Data Product Development Group. Leong holds a Bachelor and Master's Degrees in Industrial Engineering from the Purdue University in West Lafayette, Indiana, and he is a senior member of the Society of Manufacturing Engineers. Leong's email address is $<$ leong@nist.gov $>$. 